\title{
Electrocoagulation/Flotation of Textile Wastewater with Simultaneous Application of Aluminum and Iron as Anode
}

\author{
Farshid Ghanbari • Mahsa Moradi • Akbar Eslami • \\ Mohammad Mahdi Emamjomeh
}

Received: 9 May 2014 / Accepted: 7 August 2014 / Published online: 15 August 2014

(C) Springer International Publishing Switzerland 2014

\begin{abstract}
Wastewater discharged from textile industry contains a variety of polluting substances including dyes. Amongst treatment processes, electrocoagulation/flotation is a promising method for color removal from textile wastewater. In this study, the performance of a new electrocoagulation/flotation with combined Fe-Al anodes and a copper made cell as cathode was investigated for the treatment of real textile wastewater. The optimal operational condition for decolorization was $\mathrm{pH}=7,300 \mathrm{~mA}$ electrical current, $3 \mathrm{~cm}$ distance between the two anodes and $40 \mathrm{~min}$ reaction time using iron and aluminum as anode materials simultaneously. Under this condition, $98 \%$ color (ADMI) removal was achieved. Furthermore, $87 \%$ COD removal was obtained in similar optimal condition except in $400 \mathrm{~mA}$. To investigate electrical current dependency on the COD removal rate, a kinetic study was carried out and data were in good agreement with the first order kinetic model. The rate constants $(\mathrm{k})$ of COD removal were $0.0234,0.0291,0.0393$ and $0.0519 \mathrm{~min}^{-1}$ for $100,200,300$ and $400 \mathrm{~mA}$, respectively.
\end{abstract}

Keywords Electrocoagulation/flotation - Textile wastewater Decolorization ·

Combined $\mathrm{Fe}-\mathrm{Al}$ anodes

\section{Introduction}

Electrocoagulation process has been successfully used for the treatment of textile wastewater being attractive for its versatility, safety, selectivity, amenability to automation, ease of control

\section{F. Ghanbari}

Department of Environmental Health Engineering, School of Public Health, Ahvaz Jundishapur University of Medical Sciences, Ahvaz, Iran

M. Moradi $(\bowtie) \cdot$ A. Eslami

Department of Environmental Health Engineering, School of Public Health, Shahid Beheshti University of Medical Sciences, Tehran, Iran

e-mail: moradi.env@gmail.com

M. M. Emamjomeh

Department of Environmental Health Engineering, School of Public Health, Qazvin University of Medical Sciences, Qazvin, Iran 
and environmental compatibility (Thakur et al. 2009; Modirshahla et al. 2008; Rajeshwar et al. 1994). Electrocoagulation/flotation (ECF) involves the generation of coagulant in situ by the dissolution of metal ions from the consumable anode with simultaneous formation of hydroxide ions at the cathode (Bayramoglu et al. 2004; Emamjomeh and Sivakumar 2009). In ECF, pollutants are impinged up towards the surface of the ECF cell by tiny bubbles of hydrogen gas generated from the cathode (Emamjomeh and Sivakumar 2009; Chen 2004). Therefore, instead of using chemicals and microorganisms, electrons are the only employed agents in ECF being responsible for facilitating wastewater treatment (Mollah et al. 2004).

A simple ECF unit essentially involves an electrochemical cell, two electrodes as anode and cathode and a DC power supply. Aluminum and iron are usually used as anode materials, the dissolution of which produces hydroxides, oxyhydroxides and polymeric hydroxides (Kobya et al. 2010; Holt et al. 2005; Ghanbari et al. 2014). In an ECF process, coagulants which are formed through electrolytic oxidation of the sacrificial electrode, destabilize the contaminants followed by agglomeration of the destabilized phases to form flocs (Mollah et al. 2004). Then, they are floated by electro-generated hydrogen or oxygen (typically hydrogen) bubbles towards the surface of the ECF cell. In ECF, numerous electrochemical reactions occur being summarized as follows (Mouedhen et al. 2008; Chen 2004):

At the anode:

$$
\begin{gathered}
M_{(s)} \rightarrow M_{(a q)}^{n+}+n e^{-} \\
2 H_{2} O_{(l)} \rightarrow 4 H_{(a q)}^{+}+O_{2(g)}+4 e^{-}
\end{gathered}
$$

At the cathode:

$$
\begin{gathered}
M_{(a q)}^{n+}+n e^{-} \rightarrow M_{(s)} \\
2 \mathrm{H}_{2} \mathrm{O}_{(l)}+2 e^{-} \rightarrow H_{2(g)}+2 O H^{-}
\end{gathered}
$$

According to the reactions (1-4), the electro-generated metal ions $\left(\mathrm{M}^{\mathrm{n}+}\right)$ immediately undergo further spontaneous reactions producing corresponding hydroxides and polyhydroxides having strong affinity for dispersed particles as well as counter ions bringing about the coagulation (Emamjomeh and Sivakumar 2009; Mollah et al. 2004). Besides, the gases evolved at the electrodes separate particles and coagulant aggregates by lifting them up through a flotation-like process while accelerating collisions between particles and coagulant by inducing more mixing (Merzouk et al. 2011). On the whole, in electrocoagulation processes, gravity and buoyancy forces are the two main factors determining the pollutants separation mechanism and a combination of physico-chemical parameters within an electrocoagulation reactor shifts the dominant separation mechanism. Moreover, the pollutant's physicochemical properties influence its interactions within the system and eventual removal path (Holt et al. 2005; Chen 2004). In this way, various results have been reported throughout the literatures, especially about application of different anode materials. In scope of textile and organic wastewater treatment using electrocoagulation, Phalakornkule et al. (2010) stated that iron was superior to aluminum, while Ilhan et al. (2008) concluded that aluminum provided better removal in comparison with iron electrode. Furthermore, Linares-Hernandez et al. found that iron was more effective in reducing COD, whilst aluminum was more effective in removing color (Phalakornkule et al. 2010; Ilhan et al. 2008; Linares-Hernández et al. 2009). 
In this study, iron and aluminum electrodes were employed simultaneously as the anodes while a copper made ECF cell was applied to play the role of cathode. Then the effects of important operational variables in ECF process such as $\mathrm{pH}$, electrical current, inter-electrode distance, anodes materials on decolorization were investigated. Likewise, the potential of organic content removal during ECF process was evaluated based on COD removal. Although numerous studies have been carried out on the investigation of electrocoagulation/ flotation methods for wastewater treatment and separation processes, two different electrode materials (iron and aluminum) have been rarely used as anode simultaneously. Moreover, the cathode used as the ECF cell provides extensive surface area along with generating more hydrogen bubbles, thereby enhancing the electrocoagulation/flotation efficiency.

\section{Materials and Methods}

The electrochemical reactor system is schematically shown in Fig. 1a. The ECF unit mainly consists of an ECF cell (cathode), iron and aluminum electrodes (anodes), and a DC power supply. It has been stated that electrode design influences coagulant dissolution and bubble type, thereby influencing mass transfer, mixing, flotation, and pollutant removal. The electrochemical cell made of copper was used as the cathode having a diameter of $6 \mathrm{~cm}, 1 \mathrm{~mm}$ thickness and volume of $600 \mathrm{~mL}$ containing $500 \mathrm{~mL}$ electrolyte. Actually, copper made ECF cell was used to play the role of cathode to increase the surface area and facilitate the ECF process. Besides, in this condition, electroflotation was highly enhanced since the bubbles mainly originated from the cathode were distributed thoroughly and extensively from the bottom and walls of the ECF cell. An iron and an aluminum electrodes with dimensions of $7 \times 2 \times$ $0.1 \mathrm{~cm}$ were applied as the anodes simultaneously which were placed at the center of the ECF cell with a certain distance from each other. Five centimeters of the anodes were dipped in wastewater providing an effective surface area of $40 \mathrm{~cm}^{2}$. A digital DC source (Zhaoxin, 0.00-2 A, and 0.0-20 V) was also used to supply the power to the ECF system. A magnetic stirrer was used to provide mixing of the solution.

\subsection{Wastewater Samples and Experimental Procedure}

Real textile wastewater sample was obtained from a textile industry located in Zanjan, Iran and was kept at $4{ }^{\circ} \mathrm{C}$ prior to the experiments. The composition of the studied
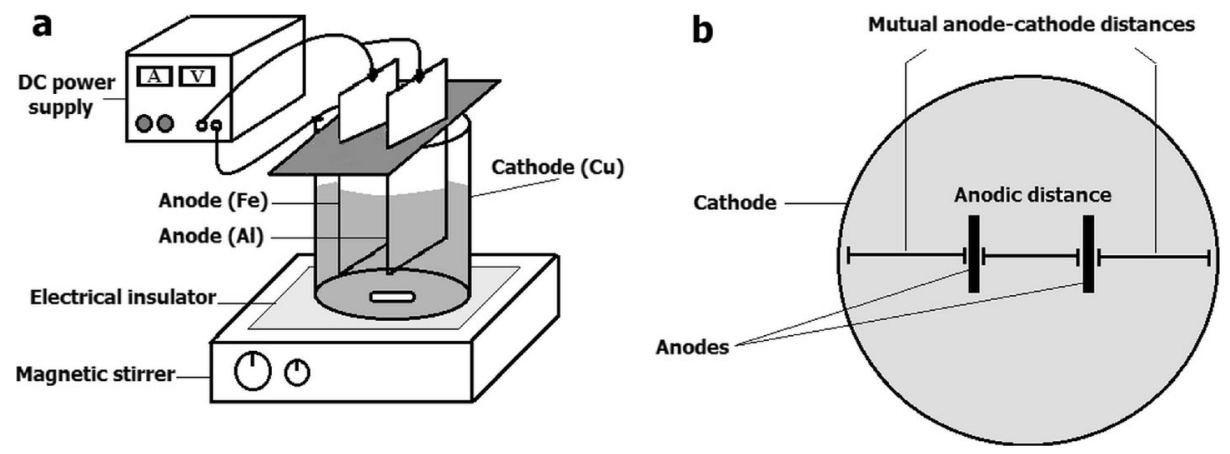

Fig. 1 a ECF setup; b Plan view of inter-electrode distances within the ECF cell 
Table 1 Real textile wastewater characteristics

\begin{tabular}{lll}
\hline Parameter & Unit & Value \\
\hline COD & $\mathrm{mg} / \mathrm{L}$ & $1,280 \pm 20$ \\
$\mathrm{BOD}$ & $\mathrm{mg} / \mathrm{L}$ & $200 \pm 20$ \\
Color & $\mathrm{ADMI}$ & $1,990 \pm 50$ \\
$\mathrm{pH}$ & & $6.5 \pm 0.05$ \\
$\mathrm{Cl}^{-}$ & $\mathrm{mg} / \mathrm{L}$ & $125 \pm 10$ \\
EC & $\mu \mathrm{s} / \mathrm{cm}$ & $820 \pm 10$ \\
Appearance & & Black \\
\hline
\end{tabular}

real textile wastewater is shown in Table 1. All experiments were conducted at room temperature. The $\mathrm{pH}$ of the solution was adjusted by adding either dilute $\mathrm{H}_{2} \mathrm{SO}_{4}$ or $\mathrm{NaOH}$. In order to evaluate the ECF process, samples were taken from the center of the ECF cell within various time intervals and were filtered through $45 \mu \mathrm{m}$. In this work, the effects of initial $\mathrm{pH}$, electrical current, inter-electrode distance and anodes materials on ECF process were studied. Moreover, the COD removal efficiency was considered to determine the effectiveness of ECF process in wastewater treatment. All chemicals used for $\mathrm{pH}$ adjustment and analytical procedures were supplied from Merck company. The experiments were all carried out twice and the average values of the results are presented.

\subsection{Analytical Methods}

To measure the wastewater $\mathrm{pH}$ value, a $\mathrm{pH}$ glass electrode (WTW 720) calibrated with standard buffers at $\mathrm{pH}$ values of 4 and 7 was used. A HACH DR 5000 spectrophotometer was applied to determine color of the samples independent of hue, according to ADMI Tristimulus Filter Method in range of 400-700 nm. Chemical oxygen demand (COD) was determined by the dichromate closed reflux, Colorimetric Method at $600 \mathrm{~nm}$ for a COD range (0-1,500 $\left.\mathrm{mg} \mathrm{O}_{2} / \mathrm{L}\right)$ in accordance with the standard methods for the examination of water and wastewater (APHA 1999), using UV-vis HACH DR 5000 spectrophotometer. Likewise, a standard potassium hydrogen phthalate solution was measured in COD range of 100 $1,000 \mathrm{mg} \mathrm{O}_{2} / \mathrm{L}$ to assure the method accuracy.

\section{Results and Discussion}

\subsection{Effect of Initial $\mathrm{pH}$}

Solution $\mathrm{pH}$ is a crucial factor in electrocoagulation process determining the solubility of the dissolvable electrode and metal speciation in aqueous solution, thereby affecting the removal efficiency of dye. Therefore, the electrochemical reactions occurring within an electrocoagulation system consisting of aluminum and iron electrodes, both used as anode simultaneously, are summarized below (Bayramoglu et al. 2004; Hu et al. 2008):

At the aluminum anode:

$$
A l_{(s)} \rightarrow A l_{(a q)}^{3+}+3 e^{-}
$$


- In acidic medium:

$$
A l_{(a q)}^{3+}+3 \mathrm{H}_{2} \mathrm{O}_{(l)} \rightarrow \mathrm{Al}(\mathrm{OH})_{3(s)}+3 \mathrm{H}_{(a q)}^{+}
$$

- In alkaline medium:

$$
\mathrm{Al}_{(a q)}^{3+}+3 \mathrm{OH}_{(a q)}^{-} \rightarrow \mathrm{Al}(\mathrm{OH})_{3(s)}
$$

At the iron anode:

$$
F e_{(s)} \rightarrow F e_{(a q)}^{2+}+2 e^{-}
$$

- In acidic medium:

$$
4 \mathrm{Fe}^{2+}{ }_{(a q)}+\mathrm{O}_{2(g)}+10 \mathrm{H}_{2} \mathrm{O}_{(l)} \rightarrow 4 \mathrm{Fe}(\mathrm{OH})_{3(s)}+8 \mathrm{H}^{+}{ }_{(a q)}
$$

- In alkaline medium:

$$
\mathrm{Fe}_{(a q)}^{2+}+3 \mathrm{OH}_{(a q)}^{-} \rightarrow \mathrm{Fe}(\mathrm{OH})_{2(s)}
$$

Regarding Eqs. 5 and 8, by applying the electrical charge, $\mathrm{Al}^{3+}$ and $\mathrm{Fe}^{2+}$ ions are formed at the anodes which are highly effective coagulants being responsible for particulate flocculation (Chen 2004). The above reactions show that $\mathrm{pH}$ determines the chemical species significantly. Hence, experiments were conducted primarily to find the most favorable initial $\mathrm{pH}$ varying in the range of 4 to 9 and the results are presented in Fig. 2.

As seen, by increasing the $\mathrm{pH}$ from 4 to 7 , the decolorization efficiency increased because the zeta potential decreases with increasing $\mathrm{pH}$ (Yıldiz et al. 2008). In addition, within low $\mathrm{pH}$, higher amount of hydrogen is generated by electro-reduction in cathode, so that less proportion of iron and aluminum hydroxide ions can be formed (Modirshahla et al. 2007). At the same time, by rising $\mathrm{pH}$ from 7 to 9 , decolorization efficiency is mitigated that is probably due to less proportion of iron and aluminum ions production which stems from oxidizing some of the hydroxide ions at the anode which in turn, decreases the metal ions opportunities to be generated via oxidizing (Modirshahla et al. 2007). Soluble species are useless in

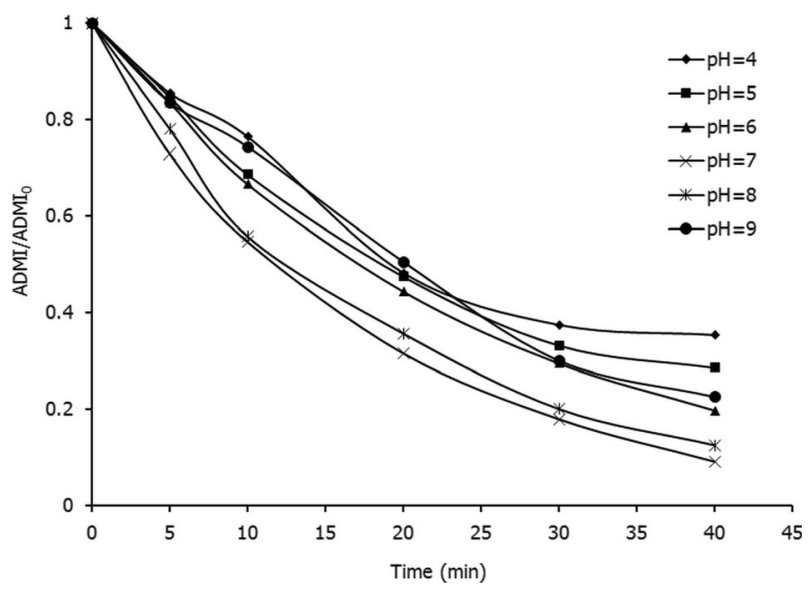

Fig. 2 Effect of initial $\mathrm{pH}$ on decolorization (electrical current $=200 \mathrm{~mA}$, distance between anodes: $2 \mathrm{~cm}$, combined $\mathrm{Fe}-\mathrm{Al}$ as anode) 
electrocoagulation processes which must be minimized through $\mathrm{pH}$ adjustment. Based on the correlation between coagulants $\left(\mathrm{Fe}^{3+}\right.$ and $\left.\mathrm{Al}^{3+}\right)$ and initial $\mathrm{pH}$ of the matrix, aluminum and iron exhibit their minimum solubility within $\mathrm{pH}$ values of 6 and 8 , respectively (Parsa et al. 2011; Ghernaout et al. 2011). When iron and aluminum were used simultaneously as the anode, the most favorable flocculation occurred at $\mathrm{pH} 7$ which corresponds to the minimum solubility of the coagulants produced during their anodic dissolution. Consequently, both very high and very low $\mathrm{pH}$ values adversely affect the flocculation and the best efficiencies of electrocoagulation occur around neutral conditions. In this study, the highest and the lowest color removals were obtained within $\mathrm{pH} 7$ and 4, respectively. Therefore, for textile wastewater studied with a $\mathrm{pH}$ about 6.5 would be advantageous for the ECF treatment of wastewater since no $\mathrm{pH}$ adjustment is needed.

\subsection{Effect of Electrical Current}

Electrical current is of high significance within all electrocoagulation/flotation processes affecting the reaction rate through the determination of coagulant dosage and bubble generation rates, bubble size, floc growth, collisions among particles and thereby, influencing the ECF efficiency (Modirshahla et al. 2008). According to Faraday's law, dissolution of electrode is related to the total charge passed which implies that the amount of adsorbent produced in the electrochemical reactor would be proportional to the electrical current (Ratna Kumar et al. 2004). In addition, electrical current is the prime factor determining the separation mechanism (Holt et al. 2005). Thus, a range of electrical current varying within 100-400 mA was investigated and the results are depicted in Fig. 3. As it is demonstrated, decolorization efficiency increased by rising the electrical current reaching to the maximum at $400 \mathrm{~mA}$. This is ascribed to the fact that at higher electrical current, more oxidation occurs within the anodes followed by higher coagulation and flocculation. Moreover, increasing electrical current brings about greater bubble density having smaller size, which effectively promotes pollutant removal by electroflotation. It was observed that the process significantly revealed the effect of electrical current in 20 min reaction time as the color of the wastewater undergoes distinct decreases by increasing the electrical current. In the present work, the highest decolorization efficiency after 40 min reaction time was obtained at $400 \mathrm{~mA}$. Nevertheless, $300 \mathrm{~mA}$ was selected because it produced relatively high efficiency along with being less energy consuming and more economical. It should be notified that the separation mechanism

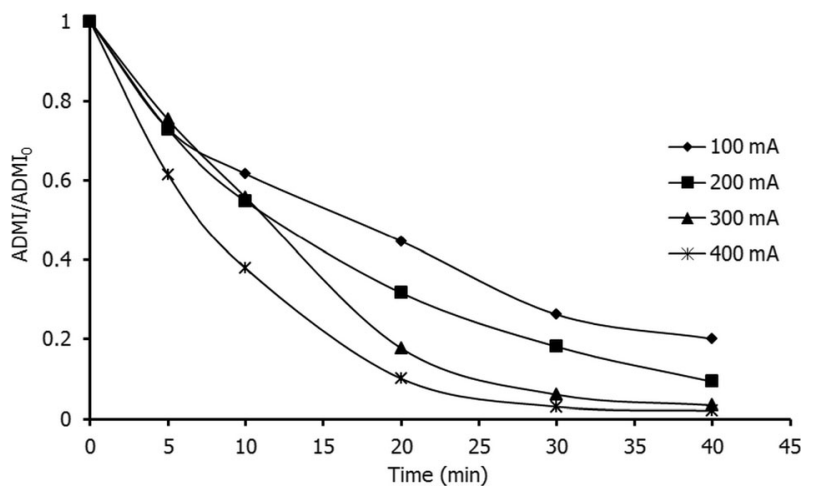

Fig. 3 Effect of electrical current on decolorization $(\mathrm{pH}=3$, distance between anodes: $2 \mathrm{~cm}$, combined Fe-Al as anode) 
was dependent on the electrical current in a way that in less than $300 \mathrm{~mA}$, the coagulated flocs were settled while at $300 \mathrm{~mA}$ and more, flotation was the dominant separation mechanism.

\subsection{Effect of Inter-Electrode Distance}

In this study, the effect of inter-electrode distance on ECF process was investigated. Regarding Fig. 1b, increasing the distance between anodes leads to the decrease of distance between each anode and cathode (ECF cell). According to Fig. 4, color removal efficiency is enhanced by increasing the distance between the two iron and aluminum anodes (i.e., reducing the distance between cathode and anode). This can be ascribed by increase of electrical current associated with decreasing the inter-electrode distance (distance between each anode and the cathode) resulting in higher collisions of the ions that enhance the coagulation. Actually, a decrease of the space between anode and cathode leads to low resistance within the electrolyte which in turn increases anodes dissolution (Ghernaout et al. 2011). Hence, more $\mathrm{Al}$ and $\mathrm{Fe}$ species were released which results in higher color removal from the solution. At the same time, by decreasing the distance between the cathode and anode, flotation is improved due to the bubbles being trapped in narrower space between the corresponding electrodes, increasing the bubble density within the inter-electrode distance. The highest decolorization efficiency was achieved with a distance of $3 \mathrm{~cm}$ between the two anodes.

\subsection{Effects of Anodes Materials}

Anode material determines the introduction of cations into the electrolyte, thereby affecting the ECF performance substantially. In the current study, three setups were investigated with exactly similar experimental conditions but with different anode materials. As it was formerly explained, iron and aluminum were the two materials being installed simultaneously as anode which have been commonly used separately but rarely in combination with each other. As can be seen in Fig. 5, using combined iron and aluminum as anode materials simultaneously, color of the wastewater is completely removed within 40 min reaction time. As it is demonstrated, the use of two aluminum anodes provides higher decolorization in comparison with two iron made anodes. It is stated that using iron as anode, brings about lower energy consumption whereas the electrode consumption is generally lower with aluminum (Ghernaout et al. 2011). In our study, the most favorable decolorization was obtained using combined iron and

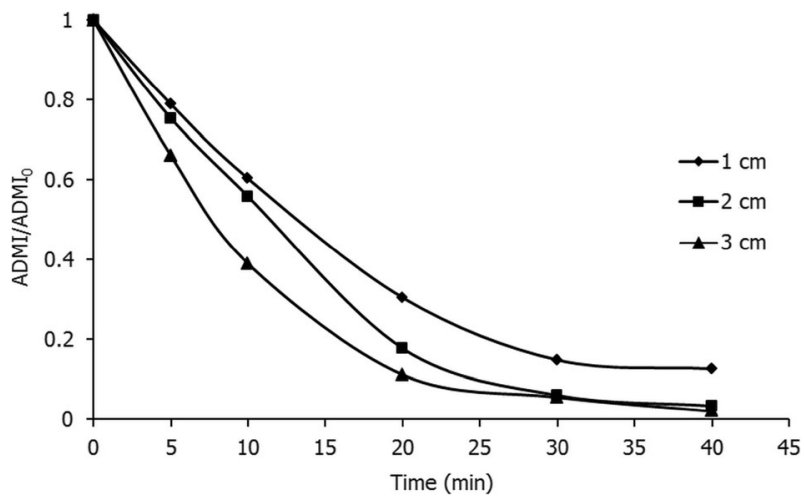

Fig. 4 Effect of inter-electrode distance on decolorization $(\mathrm{pH}=7$, electrical current $=300 \mathrm{~mA}$, combined Fe-Al as anode) 


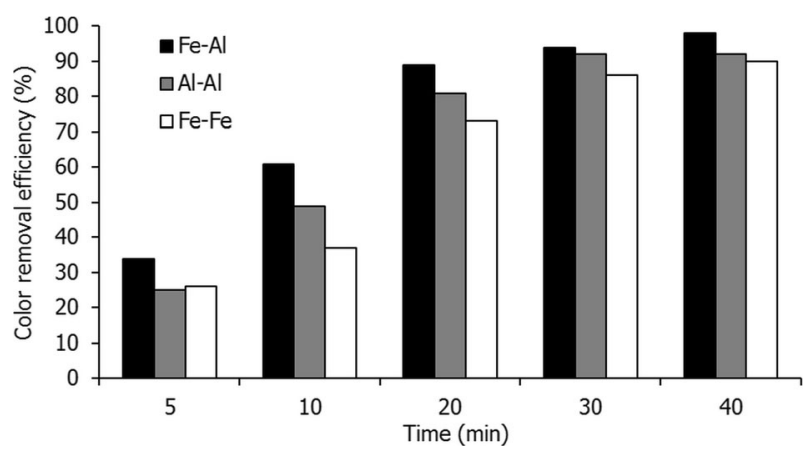

Fig. 5 Effect of anode materials on decolorization (initial $\mathrm{pH}=7$, electrical current $=300 \mathrm{~mA}$, distance between anodes $=3 \mathrm{~cm}$ )

aluminum anodes at $\mathrm{pH}=7,300 \mathrm{~mA}$, distance between anodes of $3 \mathrm{~cm}$ and $40 \mathrm{~min}$ reaction time. Having the highest decolorization efficiency in combined operational situation using iron and aluminum as anodes materials, flocs are supposed to bring about a synergist effect for the electrical accumulation of pollutants.

\subsection{Effect of Electrical Current on COD Removal and Kinetic Evaluation}

While this study mainly aims at decolorization optimization, it was also beneficial to evaluate the effect of ECF process on organic content removal of the wastewater. In this way, organic content removal of real textile wastewater based on COD removal efficiency and the effects of electrical current on it within the ECF process were examined. Generally, by increasing the electrical current, COD removal increased with time. When increasing the electrical current from 100 to $300 \mathrm{~mA}$, it was observed that the retention time of the wastewater in the ECF unit to attain a certain COD removal was shortened from $40 \mathrm{~min}$ to about $20 \mathrm{~min}$. Therefore, the retention time can be decreased dramatically by increasing the electrical current to achieve a similar efficiency. Applying 100, 200, 300 and $400 \mathrm{~mA}$, COD removal efficiencies in $40 \mathrm{~min}$ were $60 \%, 68 \%, 78 \%$ and $87 \%$, respectively.

Besides, the COD removal kinetic was evaluated in order to determine the dependency of organic content removal rate and electrical current. Figure 6 a presents the linear plot of $\operatorname{lnC} / \mathrm{C}_{0}$ versus time and demonstrates that organic matter degradation as a function of the electrical current follows a first order reaction and that the COD removal rate is directly proportional to the applied electrical current. The linear plot of $1 / \mathrm{C}_{0}$ versus time is also illustrated in Fig. $6 \mathrm{~b}$. Likewise, as shown in Table 2, the R-squared values for first and second order kinetics demonstrate that the reaction kinetic is more likely to follow the first order. The first order kinetic equation is as follows (Elmorsi et al. 2010):

$$
\ln \frac{C}{C_{0}}=-k t
$$

where $\mathrm{C}_{0}$ is the initial concentration of organic matters, $\mathrm{C}$ is the remained organic matters after the reaction, $\mathrm{k}$ is the rate constant and $\mathrm{t}$ is the reaction time. The rate constants $(\mathrm{k})$ of COD removal were $0.0234,0.0291,0.0393$ and $0.0519 \mathrm{~min}^{-1}$ for 100, 200, 300 and $400 \mathrm{~mA}$, respectively. The highest COD removal was achieved at $400 \mathrm{~mA}$ and $40 \mathrm{~min}$ retention time as the wastewater COD decreased from 1,280 to $169 \mathrm{mg} / \mathrm{L}$ (87 \% removal efficiency). Furthermore, nearly complete decolorization along with high COD removal revealed that a 

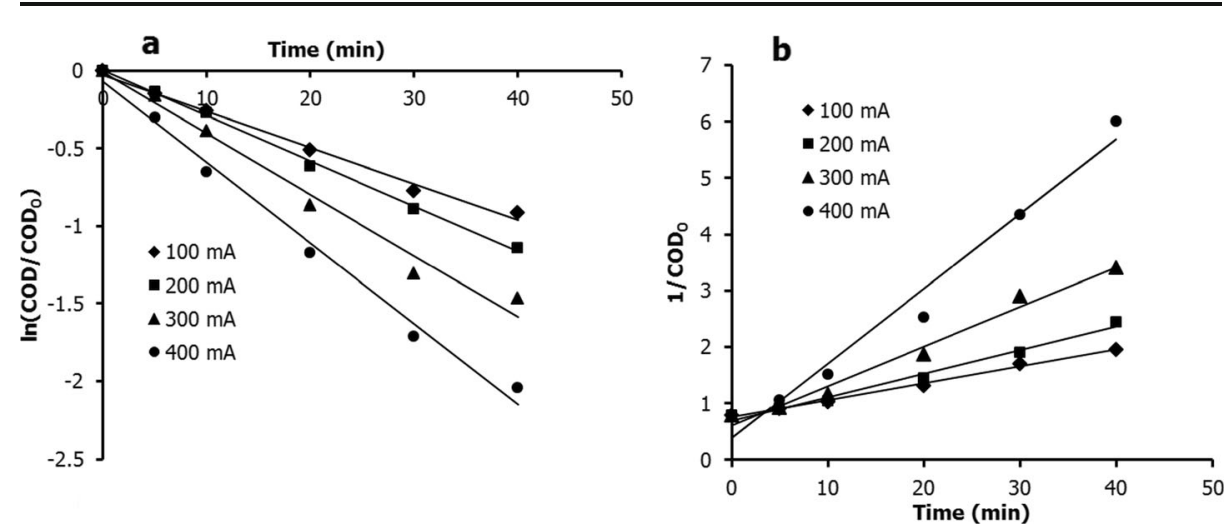

Fig. 6 Effect of electrical current on organic matters removal kinetics (a) first-order model (b) secondorder model

large amount of organic contents in the studied wastewater is allocated to the dyes having the potential to be electro-coagulated. Therefore, a noticeable proportion of COD was removed during decolorization through the ECF process.

\subsection{Energy Consumption}

Energy consumption is a crucial factor in all electrochemical processes including ECF being associated with operating cost of the process (Emamjomeh and Sivakumar 2009; Eslami et al. 2013). Electrical current correlates with the electrical energy consumption. In the current work, electrical energy consumption per cubic meter of the wastewater undergoing ECF process was calculated through the following equation:

$$
E\left(\frac{k W h}{m^{3}}\right)=\frac{\text { V.I.t }}{\text { Volume }_{\text {wastewater }} \times 1000}
$$

where V, I and t stand for average voltage of the ECF system (V), electrical current intensity (A) and reaction time (h), respectively.

As shown in Fig. 7, by increasing the electrical current, more energy is being consumed. As it was previously discussed, there was no considerable difference between 300 and $400 \mathrm{~mA}$ in color removal efficiency. Hence, $300 \mathrm{~mA}$ is economically more feasible owing to its low electrical energy consumption. Furthermore, it is hypothesized that electrolysis energy consumption can be reduced as the distance between anode and cathode decreases. Consequently, since the highest color removal rate was achieved for $3 \mathrm{~cm}$ of distance between anodes (narrowest distance of each

Table 2 Rate constant (k) and $\mathrm{R}$-squared values corresponded to degradation reactions with various electrical current

\begin{tabular}{lllll}
\hline First order & & \multicolumn{3}{c}{ Second order } \\
\hline $\mathrm{I}(\mathrm{mA})$ & $\mathrm{k}\left(\mathrm{min}^{-1}\right)$ & $\mathrm{R}^{2}$ & $\mathrm{k}\left(\mathrm{mg}^{-1} \mathrm{~s}^{-1}\right)$ & $\mathrm{R}^{2}$ \\
100 & 0.0234 & 0.9914 & $2.93 \times 10^{-5}$ & 0.9835 \\
200 & 0.0291 & 0.9976 & $4.14 \times 10^{-5}$ & 0.9867 \\
300 & 0.0393 & 0.9815 & $6.52 \times 10^{-5}$ & 0.9812 \\
400 & 0.0519 & 0.9898 & $1.30 \times 10^{-4}$ & 0.9736 \\
\hline
\end{tabular}




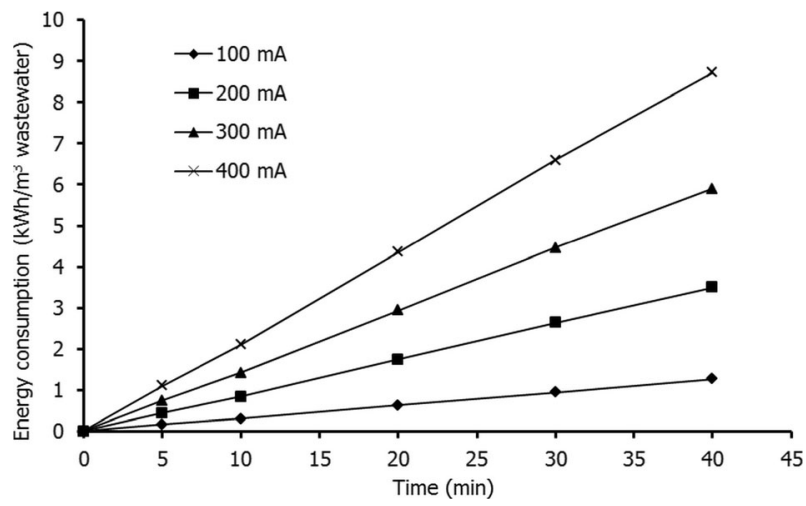

Fig. 7 Energy consumption as a function of electrical current and electrocoagulation/flotation time

anode with the cathode), the highest efficiency is obtained along with the lowest energy consumption.

As for the economy of the ECF process, the required energy consumption per cubic meter of the studied wastewater can be calculated through some of the data in the experiments conducted. Accordingly, the optimum operational parameters such as electrical current, voltage, and the reaction time to achieve the highest color removal efficiency (98\%) were determined to be $0.3 \mathrm{~A}, 14.9 \mathrm{~V}$ and $40 \mathrm{~min}$, respectively. The electrical energy consumption is calculated as:

$$
\mathrm{E}\left(\mathrm{kWh} / \mathrm{m}^{3}\right)=0.3 \times 14.9 \times 0.66 / 1,000 \times\left(5 \times 10^{-4}\right)=5.9
$$

Likewise, considering the energy related experimental conditions in which the maximum COD removal ( $87 \%$ ) was gained $(0.4 \mathrm{~A}, 16.5 \mathrm{~V}$ and $40 \mathrm{~min}), 8.71 \mathrm{kWh}$ electrical energy is required to remove COD of the studied wastewater by $87 \%$.

\section{Conclusions}

$98 \%$ color removal efficiency was achieved at $\mathrm{pH}=7$, applied current of $300 \mathrm{~mA}$, using aluminum and iron materials both used as anode simultaneously, and anodes distance of $3 \mathrm{~cm}$ in $40 \mathrm{~min}$. Likewise, the highest COD removal efficiency was $87 \%$ which was obtained in similar optimum experimental conditions as for the color removal but merely with electrical current of $400 \mathrm{~mA}$. The stated results are worth to be considered to conclude that a significant portion of COD for the studied textile wastewater was allocated to the dye; so that an efficient treatment of this wastewater is truly accomplished by the color removal in optimal conditions. In order to determine COD removal rate dependency to electrical current, a kinetic study was carried out and data were in good agreement with the first order kinetic model. Ultimately, the amounts of electrical energy required to obtain the most favorable color and COD removal for a cubic meter of the studied wastewater were 5.9 and $8.7 \mathrm{kWh}$, respectively.

Acknowledgment The authors profoundly appreciate Authorities of Shahid Beheshti University of Medical Sciences (SBMU), school of public health, for providing the experimental facilities in laboratory of water and wastewater chemistry. 


\section{References}

APHA (1999) Standard methods for the examination of water and wastewater, 20th edn. APHA, Washington DC

Bayramoglu M, Kobya M, Can OT, Sozbir M (2004) Operating cost analysis of electrocoagulation of textile dye wastewater. Sep Purif Technol 37(2):117-125

Chen G (2004) Electrochemical technologies in wastewater treatment. Sep Purif Technol 38(1):11-41

Elmorsi TM, Riyad YM, Mohamed ZH, Abd El Bary HMH (2010) Decolorization of mordant red 73 azo dye in water using H2O2/UV and photo-fenton treatment. J Hazard Mater 174(1-3):352-358

Emamjomeh MM, Sivakumar M (2009) Review of pollutants removed by electrocoagulation and electrocoagulation/flotation processes. J Environ Manag 90(5):1663-1679

Eslami A, Moradi M, Ghanbari F, Mehdipour F (2013) Decolorization and COD removal from real textile wastewater by chemical and electrochemical fenton processes: a comparative study. J Environ Health Sci Eng 11(1):1-8

Ghanbari F, Moradi M, Mohseni-Bandpei A, Gohari F, Mirtaleb Abkenar T, Aghayani E (2014) Simultaneous application of iron and aluminum anodes for nitrate removal: a comprehensive parametric study. Int $\mathrm{J}$ Environ Sci Technol. doi:10.1007/s13762-014-0587-y

Ghernaout D, Naceur MW, Ghernaout B (2011) A review of electrocoagulation as a promising coagulation process for improved organic and inorganic matters removal by electrophoresis and electroflotation. Deasalin Water Treat 28(1-3):287-320

Holt PK, Barton GW, Mitchell CA (2005) The future for electrocoagulation as a localised water treatment technology. Chemosphere 59(3):355-367

Hu C-Y, Lo S-L, Kuan W-H, Lee Y-D (2008) Treatment of high fluoride-content wastewater by continuous electrocoagulation-flotation system with bipolar aluminum electrodes. Sep Purif Technol 60(1):1-5

Ilhan F, Kurt U, Apaydin O, Gonullu MT (2008) Treatment of leachate by electrocoagulation using aluminum and iron electrodes. J Hazard Mater 154(1-3):381-389

Kobya M, Demirbas E, Dedeli A, Sensoy MT (2010) Treatment of rinse water from zinc phosphate coating by batch and continuous electrocoagulation processes. J Hazard Mater 173(1-3):326-334

Linares-Hernández I, Barrera-Díaz C, Roa-Morales G, Bilyeu B, Ureña-Núñez F (2009) Influence of the anodic material on electrocoagulation performance. Chem Eng J 148(1):97-105

Merzouk B, Yakoubi M, Zongo I, Leclerc JP, Paternotte G, Pontvianne S, Lapicque F (2011) Effect of modification of textile wastewater composition on electrocoagulation efficiency. Desalination 275(1-3): 181-186

Modirshahla N, Behnajady MA, Kooshaiian S (2007) Investigation of the effect of different electrode connections on the removal efficiency of tartrazine from aqueous solutions by electrocoagulation. Dyes Pigments 74(2):249-257

Modirshahla N, Behnajady MA, Mohammadi-Aghdam S (2008) Investigation of the effect of different electrodes and their connections on the removal efficiency of 4-nitrophenol from aqueous solution by electrocoagulation. J Hazard Mater 154(1-3):778-786

Mollah MYA, Morkovsky P, Gomes JAG, Kesmez M, Parga J, Cocke DL (2004) Fundamentals, present and future perspectives of electrocoagulation. J Hazard Mater 114(1-3):199-210

Mouedhen G, Feki M, Wery MDP, Ayedi HF (2008) Behavior of aluminum electrodes in electrocoagulation process. J Hazard Mater 150(1):124-135

Parsa JB, Vahidian HR, Soleymani AR, Abbasi M (2011) Removal of acid brown 14 in aqueous media by electrocoagulation: optimization parameters and minimizing of energy consumption. Desalination 278(1-3): 295-302

Phalakornkule C, Polgumhang S, Tongdaung W, Karakat B, Nuyut T (2010) Electrocoagulation of blue reactive, red disperse and mixed dyes, and application in treating textile effluent. J Environ Manag 91(4):918-926

Rajeshwar K, Ibanez JG, Swain GM (1994) Electrochemistry and the environment. J Appl Electrochem 24(11): 1077-1091

Ratna Kumar P, Chaudhari S, Khilar KC, Mahajan SP (2004) Removal of arsenic from water by electrocoagulation. Chemosphere 55(9):1245-1252

Thakur C, Srivastava VC, Mall ID (2009) Electrochemical treatment of a distillery wastewater: parametric and residue disposal study. Chem Eng J 148(2-3):496-505

Yıldız YȘ, Koparal AS, Keskinler B (2008) Effect of initial pH and supporting electrolyte on the treatment of water containing high concentration of humic substances by electrocoagulation. Chem Eng J 138(1-3):6372 